\title{
Using Network Analysis to Operationalize, Measure, Analyze, and Describe the Innovative and Dynamic Capacity of Local/Regional Milieu: Results from Pittsburgh
}

\author{
Aspasia Rigopoulou \\ Department of Geography and Planning, St. Cloud State University, United States
}

Copyright $\bigcirc 2017$ by authors, all rights reserved. Authors agree that this article remains permanently open access under the terms of the Creative Commons Attribution License 4.0 International License

\begin{abstract}
New dynamic city or regional economic environments are characterized by strong relational contexts. These are characterized by the existence of productive supportive local milieus involved in production, organizational and support networks and their intra and inter-network linkages as these relate to a specific industry as well as cooperative strong relations between companies of specific industries, companies and their specific milieu, and their milieu organizations. Research suggests that it is the strength, the cohesion, density, of network relationships, and the embeddedness of all the actors that may be the new predictors of and/or measures of success as these exist in the economically dynamic and innovative environments. This paper, reports on the use of network analysis to operationalize and measure the dynamism of the Pittsburgh economic region as connected with the region's ability to develop, sustain, and expand its software industry. Secondary research, informant interviews, and survey research of 165 software companies and related organizations were used to collect the data and to develop analytical constructs, while the main method of data analysis was network analysis, supplemented with qualitative and descriptive analysis of the local environment. The study documents the existence of a regional milieu that contains many elements and conditions present in dynamic regions. The analysis though showed that the relational context of the elements that constitute the milieu of the software industry were not functionally integrated and that the region lacked the dense and cohesive relational contexts asserted to exist in dynamic environments.
\end{abstract}

Keywords Economic Development, Innovation Networks, Dynamic Milieu, Local/Regional Dynamism, Social Networks

\section{Introduction}

The last three decades have stood witness to major shifts, reformulation, and debates of thought and practices surrounding the areas of economics, planning, organizational development, and policy-making as these fields relate to local and regional development.

The stagnation of regions with deep-rooted industrial traditions and large industrial concentrations, the diffused development and less than clear-cut spatial patterns and processes of industrial location and organization - conditions that characterized this period - forced policy-makers, planners, and academics to question and reexamine the premises of development theories, paradigms, practices and policies. In the search for a new understanding of the conditions of success, theoretical and empirical work started unraveling the factors that were helping some regions adapt and perform better than others. Researchers had focused their attention on the success stories of regions such as Third Italy, Toyota City in Japan, and Route 128 in Boston, or Silicon Valley in the United States. On one hand, they analyzed firms' investment, organizational, and innovation behavior and strategies through micro-level analyses and case studies; on the other, they sought to identify the elements within regions, which appeared to stimulate regional development, progress, transformation, and success.

These efforts provided valuable insights about the spatial organization; inter- and intra-firm organizational behavior; and cultural, social, and political climates, environment, and behavior characterizing the successful regions. They also provided evidence for the emergence of a new model of location dynamism and regional development. This was observed in the spatial concentrations of small interlinked and specialized clusters of firms, in the location decisions of large firms which 
under certain conditions appeared to behave differently than those characterizing the branch plant economy model, and in the transformation and renewal of old industrial regions $[1,2,3,4]$ The most important finding to emerge from this massive search for the conditions of success centers on the interface of the local milieu or environment, the network characteristics of the local economic, policy, and other actors, and the technological or organizational innovation of individual firms, i.e., the introduction of new products, processes, and organizational devices $[5,6,7,8$, $9,10]$. This finding acts as the basic premise of the new way of thinking about local and regional development and dynamism.

The local milieu, or environment, along with the various production and organizational relations/networks takes center stage in this new model. These elements are held to be the forces which determine the factors and variables of innovative behavior, foster and stimulate regional development, and generate innovative behavior and local/regional dynamism [11, 12, 13, 14, 15, 16]. Informed by various empirical studies in Europe and North America, and organized under the theoretical work of the Groupe de Recherché European sur les Milieux Innovateurs (GREMI), the "new model" highlights two conditions that appear to characterize dynamic environments:

a) the existence of a local milieu/environment that is supportively involved in the creation, expansion, and sustainability of specific production or organizational networks and their intra- and inter-network linkages; and

b) the existence of cooperative relations between companies of specific industries as well as supportive relationships between companies and the appropriate networks of their local milieu or environment.

The existence or absence of these two conditions formulates the main thesis of the model, as they are asserted to determine the conditions of local/regional dynamism and growth.

\section{The Research Content}

\section{Study Site and Purpose of the Study}

The interplay and contribution to local and regional development of the ideas of innovation, networks and the local milieu was the primary focus of this study. Grounding

1 The GREMI group, created in 1985 in Europe, is composed of about fifteen predominately European and some American research groups. Its main aim was the development of a common methodology and a theoretical perspective to study and interpret innovative behaviors and technological innovation within local/regional context. Its earlier research efforts focused on the effects the local/regional milieu or environment has on the innovative capabilities of the firms. GREMI's more recent research efforts examine the spatial effects of the network behavior of firms. the research in the Pittsburgh economic this study sought to primary examine and evaluate how the Pittsburgh economic region conforms to the "new model" already formulated and secondarily to test out a new methodological approach in the study, measurement, and operationalization of the relational context of the local milieu as it relates to the Software Industrial (SI) cluster.

The SI is the main industrial sector of the Information and Communication Products and Services industrial cluster, with a large variety of applications in the regional economic sectors. In the context of this study, the SI is defined through its primary technology sectors as seen in the sectoral specialization of its leading companies. The primary technology sectors include the following: a) Networking and Connectivity; b) Client Server and Distributed Systems; and c) Knowledge-Based Systems and Neural Networks;

The SI cluster was used because: a) the SI was a relative newcomer during the time frame of the study to the industrial make-up of the region and as such it has not been studied as extensively as the older industries; and b) similar research during that time indicated that milieu and network connections and effects appeared more prominently within High Technology industrial sectors $(17,18,13,19)$ such as the SI. Simply put, if the Pittsburgh economic region conforms to or exhibits elements of the "new model," evidence can be seen more readily through an industrial sector like Software.

The initial evidence that framed this study came from secondary research and discussions with local technology and economic-development actors. Through these sources, the study established the existence of broadly sketched networks of support, cooperation, transaction, and interaction relations among milieu organizations, among software companies, and between the milieu organizations and software companies. The existence of these networks indicated the existence of activity in the local/regional environment and provided the grounds on which to base a more thorough and complete investigation.

In this study, the local milieu is defined as an invisible entity composed of public and private actors in the form of organizations, institutions, and companies; various resources including financial and human; a local social and technical culture; and various internal and external relationships. The study also extends the concept of network beyond the immediate tacit and informal relational context of individual firms, their explicit linkages with selected partners, the intra firm organizational hierarchy, or its markets, to also include the following:

a) Relations between public, private organizations and institutions of the local milieu as these relate to the software industry;

b) Relations between software companies; and

2 It was estimated that there were over 310 local/regional software firms in 1994, occupying a work force of 9,800 in the region [2]. 
c) Relations originating from the local milieu to the software companies.

The main attribute of both the milieu and the various networks within the GREMI framework is the synergetic and cooperative nature, which characterizes their inter- and intra- relationships. This attribute allows the actors of the various networks and the milieu to interact and cooperate in terms that are not purely and/or exclusively market-dictated [20, 21, 22, 5, 6, 23, 24, 25, 26, 27]. In the context of this study and paper the local milieu during the study period was composed of the following organizations, which are grouped by their primary function with the scope of the software industry:

Table 1. Milieu of the Software Industry in the Pittsburgh Economic Region, 2000

\begin{tabular}{|c|c|}
\hline Specialization & Organizations \\
\hline $\begin{array}{l}\text { Administrative/general Support } \\
\text { and Advocacy } \\
\text { Organizations/High-tech Policy }\end{array}$ & $\begin{array}{ll}- & \text { Pittsburgh High Technology Council (PHTC) } \\
\text { - } & \text { Software Business Forum; (SBF) } \\
& \text { Working Together Consortium; (WTC) }\end{array}$ \\
\hline $\begin{array}{l}\text { Public and Economic Development } \\
\text { Policy }\end{array}$ & $\begin{array}{ll}\text { - } & \text { City of Pittsburgh Government; City of Pittsburgh Economic Development; } \\
\text { - } & \text { Allegheny County Government; County Department of Economic Development; } \\
\text { - } & \text { Economic Development Offices of regional governments; } \\
& \text { State Government }\end{array}$ \\
\hline General Policy \& Support & $\begin{array}{l}\text { - } \quad \text { University of Pittsburgh (PITT); } \\
\text { - Carnegie Mellon University (CMU); }\end{array}$ \\
\hline Funding/Financing & \\
\hline Non-Profit Funding & $\begin{array}{l}\text { - } \quad \text { Ben Franklin Technology Center (BFTC); } \\
\text { - } \quad \text { Enterprise Corporation (EC); }\end{array}$ \\
\hline Banks & $\begin{array}{l}\text { - } \quad \text { Mellon Bank; PNC Bank; Other Banks; } \\
\text { - Mellon Ventures; }\end{array}$ \\
\hline Venture Capital & $\begin{array}{ll}\text { - } & \text { Venture@PNC } \\
\text { - } & \text { CEO Venture Capital Fund; } \\
\text { - } & \text { Pittsburgh Seed Fund; Pennsylvania Growth Fund; } \\
\text { - } & \text { Adams Capital; } \\
\text { - } & \text { Birchmere Investments; } \\
\text { - } & \text { Wesmar Partners; } \\
& \text { C\&L Ventures; Other Venture Firms; }\end{array}$ \\
\hline Public Funding / Financing & $\begin{array}{l}\text { - Urban Redevelopment Authority’s (URA) Business Development Center; } \\
\text { - Commonwealth of Pennsylvania Dept. of Economic and Community Development. }\end{array}$ \\
\hline $\begin{array}{l}\text { Software business related Support } \\
\text { organizations }\end{array}$ & $\begin{array}{ll} & \text { University of Pittsburgh (PITT) Business Development Center; } \\
\text { - } & \text { Carnegie Mellon University (CMU)-Entrepreneurial Development Center; Other business } \\
\text { centers; } \\
\text { - } \quad \text { Other Business Development Related Centers }\end{array}$ \\
\hline Research General & $\begin{array}{ll} & \text { CMU-Software Engineering Institute; } \\
\text { - } & \text { University of Pittsburgh Super Computing Center. }\end{array}$ \\
\hline $\begin{array}{l}\text { Educational/ Research \& Provision } \\
\text { of High Tech. Professionals to } \\
\text { Companies, and sources of } \\
\text { software companies }\end{array}$ & $\begin{array}{l}\text { - } \quad \text { PITT-Computer Science department } \\
\text { - } \quad \text { CMU-Computer Science and other related departments; } \\
\text { Other local/regional Universities }\end{array}$ \\
\hline $\begin{array}{l}\text { General Support (provision of } \\
\text { administrative personnel to } \\
\text { companies and software related } \\
\text { milieu organizations) }\end{array}$ & $\begin{array}{ll} & \text { PITT General; } \\
\text { - } & \text { CMU General; } \\
\text { - } & \text { Other local/regional Universities; } \\
\text { Technical schools. }\end{array}$ \\
\hline
\end{tabular}

Source: [28] 
Within this framework and with an exploratory and descriptive orientation this paper aims to:

1. To establish the existence or absence of relationships between: a) the software industry and the local milieu; b) the local milieu and its various actors; and c) the software industry and its various actors;

2. To identify, describe, and evaluate the nature of these relationships;

3. To test the propositions of the GREMI theoretical framework and to create a methodological and analytical approach to measure the density/cohesion and other characteristics of network relations that have been used to describe the relations of fast growing and dynamic environment, but which have not been preciously measured.

4. To assess empirically the local milieu's involvement in the process of creating, supporting, sustaining, and expanding the local software industry network as well as nurturing inter- and intra-network linkages and relationships.

Study Questions

In the context of these objectives, the study posed the following questions:

1. Do local milieu actors relate with each other? If not, why not? If so, how do they relate with each other and what are the characteristics, the content, the density/cohesion of their relationship?

2. Do local software companies relate with the local milieu? If not, why not? If so, how do they relate with the local milieu and what are the characteristics, the content, and the density/cohesion of their relationship?

3. Do local software companies relate with other local software companies? If not, why not? If so, how do they relate to each other and what are the characteristics, the content, and the density/cohesion of their relationship?

4. What has been the local milieu's contribution to the process of creating, sustaining, and expanding the local software network?

Through a combination of secondary research with the literature of GREMI, informant interviews with local economic development, high technology experts, and representatives of the local/regional software industry the above relations were operationalized as follows:

Table 2. Intra Milieu Relations/Networks of importance to the Pittsburgh Software Industry

\begin{tabular}{|c|c|}
\hline Intra Milieu Relations / Networks & Operationalization of the Relations /Networks \\
\hline Boundary Penetration and Interaction/Coordination Relations & $\begin{array}{l}\text { 1. Participation in the board of directors of other organizations; } \\
\text { 2. General, Formal, or informal interaction with other local } \\
\text { organizations; } \\
\text { 3. Attending same meetings and functions; and } \\
\text { 4. Participation in or support of the same activities or projects. }\end{array}$ \\
\hline $\begin{array}{c}\text { Support \& Transaction Relations for Transfer of Material } \\
\text { Resources }\end{array}$ & $\begin{array}{l}\text { 1. Loaning or borrowing resources for completion of specific } \\
\text { projects; and } \\
\text { 2. Providing technical or general advice. } \\
\text { 3. Providing or receiving funding and financing from other local } \\
\text { and/or regional organizations. }\end{array}$ \\
\hline Communication and Information Exchange Relations & $\begin{array}{l}\text { 1. Sending or receiving of general purpose messages; and } \\
\text { 2. Exchanging pertinent information. }\end{array}$ \\
\hline
\end{tabular}

Source: [28]

Table 3. Intra Software Relations/Networks of importance to the Pittsburgh Software Industry [28]

\begin{tabular}{|c|c|}
\hline Intra-Software Relations/Networks & Operationalization of the Relations / Networks \\
\hline Transaction Relations for Transfer of Material Goods & $\begin{array}{l}\text { 1. Providing or receiving business referrals/ information that lead to } \\
\text { business transaction; and } \\
\text { 2. Participation in a formal business relationship. }\end{array}$ \\
\hline $\begin{array}{c}\text { Support and Transaction Relations for Transfer of } \\
\text { Non-Material Goods }\end{array}$ & $\begin{array}{l}\text { 1. } \quad \text { Exchanging Pertinent Information; } \\
\text { 2. } \quad \text { Loaning or borrowing tools, equipment, or other resources; and } \\
\text { 3. }\end{array}$ \\
\hline Communication / Interaction Relations & $\begin{array}{l}\text { 1. } \\
\text { 2. } \\
\text { 3. }\end{array}$ \\
\hline
\end{tabular}

Source: [28] 
Table 4. Milieu to software Relations/Networks of importance to the Pittsburgh Software Industry

\begin{tabular}{|c|c|}
\hline $\begin{array}{c}\text { Milieu to Software Industry } \\
\text { Relations/ Networks }\end{array}$ & Operationalization of the Relations/Networks \\
\hline $\begin{array}{c}\text { TRANSACTION RELATIONS } \\
\text { Transfer of Material Resources }\end{array}$ & $\begin{array}{ll}\text { 1. } & \text { Receiving funding; } \\
\text { 2. } & \text { Receiving financing; } \\
\text { 3. } & \text { Receiving information or referrals that led to business } \\
\text { transactions }\end{array}$ \\
\hline Transfer of non-Material Resources & $\begin{array}{l}\text { 1. Receiving advice and guidance for business startup; } \\
\text { 2. Receiving general purpose information about local industry and } \\
\text { resources; and } \\
\text { 3. Receiving information concerning research and technological } \\
\text { advice. }\end{array}$ \\
\hline SUPPORT RELATIONS & $\begin{array}{ll}\text { 1. } & \text { Providing Scientific Personnel; } \\
\text { 2. } & \text { Providing appropriate academic and training programs; } \\
\text { 3. Providing appropriate research environment; and } \\
\text { 4. Providing situations that allow for scientific exchanges and } \\
\text { business networking opportunities. }\end{array}$ \\
\hline INTERACTION RELATIONS & $\begin{array}{l}\text { 1. Attending local meetings organized by local milieu } \\
\text { organizations; and } \\
\text { 2. Participating in the same local organizations (industry related, } \\
\text { public special and general-purpose organizations, etc.). }\end{array}$ \\
\hline
\end{tabular}

Source: [28]

\section{Methodology}

Data Collection: Secondary research and informant interviews were used in the development of a survey instrument administered to CEOs of local software companies via mailings of the questionnaire and personal interviews. This produced an 80 percent response rate. Analysis of the software questionnaire, secondary research, and informant interviews were in turn used to create a second questionnaire that was administered to representatives of the local software related milieu. The milieu surveys produced 100 percent response rate.

Data Analysis: The main method of data analysis in this study was network analysis. The method's emphasis on the different kinds of relations among social actors, as well as the patterns of such relations and their implications for the social system, has made it very popular within the social and behavioral sciences $[29,30$, 31].

There are two major premises that guide network analysis and distinguish it from other analytic methods. The first premise is centered on the belief that any actor participates in social systems that include other actors. The actors of a particular social system act as reference points in each other's decisions, and the type of relationship a particular actor may have with other actors in the system can affect and influence that actor's decisions, beliefs, actions, and ideas. The second premise states that "the structure of relations among actors, and the location of individual actors in the network have important behavioral, perceptual, and attitudinal consequences both for the individual units and for the systems as a whole"[32 p13]. This premise explains the important emphasis given in network analysis to the discovery, description, and analysis of the various relations that link social positions within a system. This knowledge of how social relations are organized within a network is crucial, since it allows for the detection of important and emerging social phenomena, and the identification of changes that have occurred in systems or individuals.

Unlike traditional social science research, which views, classifies, analyzes, and measures the social world solely in terms of attribute data (sex, age, value of goods, earnings, etc.) and other intrinsic characteristics of people, objects, and events, network analysis relies on relational data (while still giving consideration to attribute data, since it does not view the two as polar or mutually exclusive), emphasizing relational measures which "capture emergent properties of social systems which cannot be measured by simple aggregations of at tribunal data....and which may significantly affect both system performance and the behavior of individual members" [32 p11] For example: the structure of communication relations or various support relations among milieu organizations in the Pittsburgh economic region may affect the ability of the local environment to diffuse innovation, or its adaptiveness and rate of response to economic changes and innovative technologies.

The core of the network analysis method is to create matrices in which the rows and columns represent members of the network. At the intersection of each row and column is either a 0 or a 1 , indicating either the absence or presence of a relationship between the given members of the network. Various measures describing the network are then generated through any number matrix algebra manipulations and computations on the elements of the matrix [33, 32]. This study used UCINET's Network analysis routines found in its Network analysis submenu.

The data was analyzed with the network analysis program known as UCINET [34, 35]. UCINET is a menu-driven Windows program incorporating a diverse 
collection of network techniques and network theoretical traditions. It is a mathematics-based program using matrix algebra based-algorithms in its analytic procedures. As such, it does not provide for data testing in the tradition of statistics. The techniques are diverse in terms of both what they do (detection of cohesive subgroups, measurement of centrality, etc.) and where they come from (in the sense that they have been developed by different individuals with different mathematical, methodological, and substantive points of view). The main part of the program used to analyze data in this study, was found in the NETWORK sub-menu. This sub-menu allowed for an analysis of network density, distance, reachability, network centralization, and clique identification via use of matrix algebra computations on the network matrices.

\section{Definition of Network and Units of Analysis}

As defined for methodological purposes, a network represents a specific kind of relation that links a certain set of actors, objects, or events within a social system such as a region, city, organization, or classroom [36]. A typical analytical design involves the investigation of network relations within a larger system, with two or more lower levels of units, which constitute the actors or nodes. In the context of this study, the larger system is the Pittsburgh Economic Region. The smaller units are: a) the software industry, composed of local/regional software-consulting and software-producing companies; and b) the software-related milieu, composed of various public, private, and non-profit organizations; banks and venture capital firms; research and educational institutions; and local/regional governmental units.

\section{Level of Analysis}

Network analysis analyzes relational data at various levels. At the simplest level, the egocentric network analysis starts with individual actors; then we move to the dyad, triad, etc. After the triad, the most important level of analysis is the complete network. At this level of analysis, relational data is used to establish the existence of distinct positions within the system and describe the structure and nature of relations among these positions. The complete network will be the level of analysis used in this study. Here the total network (milieu) as it relates to the software industry is viewed as an invisible system composed of various kinds of organizations/actors. The interaction of these actors with other system actors creates networks of various relational contents, such as financial networks, transaction networks, support networks, etc. Therefore, in order to analyze the total network, this study examines and analyzes each of the relevant component networks. For purposes of analysis - and as informed by the theoretical framework - this study breaks the total network into three sub-relational networks:
- The organizational environment--or as it is called elsewhere in the study, the milieu--of the software industry. This includes the relational networks among milieu actors.

- The software-industry environment represented by the various software companies. This includes the relational networks between the companies.

- The milieu and software-industry environment. This includes the relational networks that exist between the milieu and the software companies.

\section{Data Representation}

Network analysis offers two ways to represent and analyze relational data: a) sociograms or graphs which use graph theory for their analysis; and b) algebraic representations which use matrix algebra for their analysis. This study used matrix algebra as it is incorporated into the UCINET ${ }^{1}$ analytic program [34, 35] to analyze and describe the structural characteristics of the local networks.

\section{Specific Measures and Data Analysis}

Within its exploratory and descriptive character, this study's main objective is to evaluate the Pittsburgh economic region's dynamism and innovative capacity as these relate to its ability to develop, sustain, and expand its software industry. Within the framework of network analysis, the study provides this evaluation through:

- Identification and examination of the relevant networks as they apply to intra- and interrelations of milieu organizations and software companies;

- Description of the networks' external and internal relational content, structure, and organization;

- Measurement of the external and internal cohesiveness of relations in the networks.

Similar research which was carried out in North America and Europe [37, 38, 39, 40, 22, 3, 13, 41, 42, 43, 44, 45] but which did not include any attempts at measurement-have identified network density as an important characteristic present within dynamic and innovative local environments. This research indicates the existence of dense networks of relations--including financial, funding, advice, communication/information, cooperation, and general support networks--in innovative environments. It is inferred that the higher the density of relations one finds among local actors within different relational contexts, the higher the ability of the local environment to grow, adapt to changes, create and diffuse innovation, and generally facilitate local/regional development will prove to be.

In the context of the analytic framework, though, density is only a reflection of network cohesion [46]. In this respect, therefore, this analysis measures network cohesion as reflected in measurements of the networks' density, while measures of network(s) centralization, and clique 
identification provide a picture of networks' organization and structure. Generally, network density measures the average level of linkage between actors of a network. The density of a network, however, depends on two other factors of network structure: a) the inclusiveness of the network; and b) the sum of the degrees of its points. The sum of degrees represents the total number of relations actors of a network either direct to other actors (these relations are called out-degrees), or have directed at them by other actors (in-degrees). Inclusiveness represents the number of points or actors contained within the various connected parts of the network. It is measured as a proportion of the number of connected points over the number of the total potentially connectable points [46]. The higher the inclusiveness and sum of degrees, the higher a network's density will be, and vice versa. Density as a measurement, though important, is in many respects difficult to interpret. This difficulty stems from the fact that even small networks can never have a density of 1 , which would occur if every actor were connected with every other actor. The same holds true for inclusiveness, as well as cohesion: the larger the network, the more difficult it becomes to achieve total connection. Despite this difficulty, these measurements, in the context of this study and its descriptive and exploratory nature, provide a way to study the local environment and reveal some of its limitations and structural defects. For example, analysis of the intra-milieu relations reveals that most of the venture capitalists are not involved in the relational networks of the milieu. This fact, in addition to validating the claims of the software companies, indicates a limitation of the milieu - the lack of participation of venture capital within the context of the software industry. It also highlights the need for incorporating into the functioning of the milieu ways for venture capitalists to become more involved.

While cohesion is reflected in measurements of network density and centralization, it is also measured in terms of the reachability and distance of actors within the various networks. Reachability within a network represents an actor's ability or inability to reach other actors. In the context of this study, the UCINET program used for analysis provided a reachability matrix representing the lack (0) or existence (1) of a path connecting two actors. By simple algebraic manipulation of the matrix, a reachability percentage was derived for each relational network.

Distance, meanwhile, represents the length of the shortest path connecting two actors in a network. The shortest distance in any network is 1 , which represents a direct connection between actors. Distances of 2 and above represent indirect relations.

In addition to these measurements, the networks are analyzed in terms of their overall level of centralization and their actors' centrality, using Freeman's methods of measurement for both concepts [47, 48].

Freeman has introduced various methods of measuring the centrality of actors. Among these the one used in this paper is the point degree centrality, which is generally based on either the out-degrees or the in-degrees of individual actors within a network. Point degree centrality generally represents how well-connected an actor is within a specific network. Depending on the relational context, the measurement can also indicate the dominance of a specific actor within the network. Measuring point centrality consists simply of counting how many relations an actor initiates with or receives from others. Within the context of reciprocal relational networks, one of the two measurements is used. In the context of non-reciprocal relations, as is the case for the relations of the networks in this study, each actor will have two- point measurements: one for his/her out-degrees and another for his/her in-degrees. In the context of this study, only the out-degrees are considered. This treatment of actor centrality is referred to as local centrality.

The next measurement provided by this analysis dealt with network centralization. Network centralization represents the tightness of the network organization around its central point/actor and is based on the various conceptions of point centrality. Centralization and centrality can thus instructor guide the reasoning regarding the functioning of networks in relation to the involvement and closeness of specific network actors due to their position. The identification of specific central actors in conjunction with the overall network centralization measure can also indicate a lack of involvement from other actors who may be important in terms of resource allocation or decision-making.

Although measurements of network centralization and actor centrality are important, they do not clearly identify whether the central point(s)/actor(s) are clustered within a specific area of the network as a specific set/group, or spread throughout the network. In order to evaluate the internal organization of the networks, the study analyzed networks in terms of the existence of cliques. This analysis, in conjunction with the analysis concerning actor centrality, allowed for a closer examination of individual actors' roles and places within the networks.

As a concept, a clique represents a unique grouping of actors within a network. The analysis of a network in terms of cliques and by the use of the UCINET computer analytic program [34] provides the opportunity to detect reciprocal (strong) ties and non-reciprocal (weak) ties among groups of network actors. More specifically: the existence of cliques within a network of undirected or reciprocal relations denotes strong relational sub-groups. When a network consists of directed or non-reciprocal relations, clique analysis identifies only those subgroups that have reciprocal relations, and thus the existence of cliques again indicates strong relational sub-groups. In the context of directed relations, when the issue of reciprocity (or, in network terminology, the direction of the relations) is ignored and only the existence or absence of relation is examined, the analysis then treats all relations as 
reciprocated, leading only to the identification of only weak cliques.

In the context of this study, clique analysis revealed the existence of directed, non-reciprocated, weak relations among actors' sub-groups. In the context of this study - and under the theoretical suggestions of GREMI, in which the unified efforts, inclusiveness, participation, cooperation, and strong ties of all actors are implied - the existence of cliques is therefore important. Cliques may be an indication of the fragmented nature of relations, especially if the cliques' density is higher than the total network density, membership is mostly exclusive in terms of the number of network actors included or if the cliques represent indirect connections with an average distance of two or more. These distances in the context of cliques are referred to as levels. A level-1 clique represents directly connected actors, while a level-2 clique represents actors who may be connected either directly (at distance 1) or indirectly through a common neighbor at level 2 . The higher a clique's level, the larger distance one can find between actors, and, therefore, the weaker, more distant, and less effective the relation is considered to be. It has been argued that cliques at levels 2 or higher, although important when describing structural characteristics of networks, do not adhere to the strict definition of a clique, which presupposes a closeness of linkage found only in cliques up to level 2.

\section{Study Limitations/Disclaimer}

At this point, a disclaimer is necessary about the relational measurements of the study. The uniqueness of this study - being the first attempt to test the propositions of the GREMI ideas, as well as the first attempt to measure the strength of relations - is its major limitation. Without similar studies, the measurements provided in this study can only act, at this point, as additional descriptive elements of the relational content of the local/regional milieu and software industry. To become more meaningful this study must be duplicated in different environments containing the same industry or even within the Pittsburgh environment at a later point in time utilizing relative measurements of density and cohesion. This duplication will provide for the cross-comparative analysis and evaluation of different regional milieu, and will further validate the theoretical propositions, as well as the methodology, of this study.

It is also important to note that there are no universal or specific set ranges on the basis of which one can evaluate measurements of density or centralization. There are only the general ranges of 1 and 0 as the two extremes by which to evaluate different measurements of network structure. Thus, the following arbitrary ranges were set at a .20-point interval for the purposes of clearer description, discussion, and presentation of the results of the analysis, with the understanding that there is no methodological justification.

Table 5. Network Density Evaluation Ranges 0-1

\begin{tabular}{|c|c|}
\hline Categories & Ranges \\
\hline Non-connected & $0.00-0.20$ \\
\hline Slightly Connected & $0.21-0.40$ \\
\hline Moderately Connected & $0.41-0.60$ \\
\hline Highly Connected & $0.61-0.80$ \\
\hline Totally Connected & $0.81-1$ \\
\hline
\end{tabular}

Source: [28]

Table 6. Network Centralization Evaluation Ranges 0 - 100\% [28]

\begin{tabular}{|c|c|}
\hline Categories & Ranges \\
\hline Non-centralized & $0-20 \%$ \\
\hline Slightly Centralized & $21 \%-40 \%$ \\
\hline Moderately Centralized & $41 \%-60 \%$ \\
\hline Highly Centralized & $61 \%-80 \%$ \\
\hline Totally Centralized & $81 \%-100 \%$ \\
\hline
\end{tabular}

Source: [28]

Although measurements of density, centrality, distance, reachability, and clique identification can act as means of evaluating the local environment, this study set some additional criteria which were empirically established and analyzed. One of the criteria established for a positive local environment was the existence of various local organizations involved in or related to the software industry through their provision of financial, human, support, and educational resources to the industry. The other criteria established for a supportive environment were representation of the software industry on the boards of various milieu organizations, and the existence of software companies which were either spin-offs of local companies or the start-ups of locally trained people.

Additionally, to provide a more complete evaluation, this study, through the personal and survey questionnaires, asked the software companies and milieu organizations to: a) describe the elements that, in their opinion, constitute a supportive environment; and b) evaluate the local environment in terms of the criteria they had just identified. The responses were categorized using a qualitative, content-based approach, and described and analyzed through the use of basic statistics. Results of the qualitative analysis, which are not included in the current work, supplemented and validated the results of the network analysis and informed the policy recommendations presented at the end of the current paper.

\section{Results of Network Analysis}

\section{A. Intra-Milieu Relations}

The main question that guided this part of the analysis was: Do milieu actors relate with each other? If not, why 
not? If yes, how do they relate to each other? What is the content, and characteristics of their relations? The significance of dense/cohesive milieu networks of various relational contexts is directly connected to the synergetic and supportive ability of the milieu a condition that is hypothesized in the GREMI literature as important for dynamic milieu driven growth, and generation of innovative activity.

More explicitly the existence of a dense boundary penetration network rests on the assumption that the higher the levels of participation in key positions on the boards of directors of software milieu-relevant organizations, the more interconnected the organizations will be $[49,50]$. This implies higher levels of cooperation, understanding and unified decisions in matters of both policy and individual program implementation. In addition to characterizing an organizationally synergetic and embedded milieu, this function is directly connected to the environment's ability to perform functions, implement programs and policies which provide for the readiness of the milieu to effectively respond to changes (economic, financial, and technological fronts) and thus safeguard both the territory and the industry. Similar significance is attributed to the existence of a cohesive/dense interaction network as this is directly tied to the ability of local actors to become aware of each other. Acquaintance in turn can contribute to repeated interactions and the eventual development of trust. These conditions are important for the efficient and effective functioning of a milieu [51, 52]. It is interested to note that the existence of a dense network of social relations has been associated with the success of Silicon Valley [13] and that of the industrial districts of Third Italy $[53,54,55]$.

The cohesiveness of a Communication and Information Exchange network is related to access and information flow. These are condition that increase levels of awareness of events that may have a direct or indirect influence for example on the software industry and contribute to the milieu's response and readiness rate. Such information may be news about the existence of a new fund that may provide additional money for start-up companies, the passing of a tax regulation that may decrease business taxes, or the availability of a software-relevant business assistance incentive package. It may also include information about a sudden crisis emanating from changes of the general local national and international investing, economic and technological environments (e.g., the recent announcement of changes in investors' choices away from software and into e-commerce and dot-com companies and technologies). As in the case of all the other networks the significance attributed to the support and transaction network rests on its contribution to the milieu's synergy, dynamism, and overall levels of readiness and ability for growth, innovation and change $[25,26,27,49,50]$.

Table 7. Results of Network Analysis for Intra-Milieu Relations / Networks

\begin{tabular}{|c|c|c|c|c|c|c|c|}
\hline Relation / Network & \multicolumn{7}{|c|}{ RELATION/NETWORK MEASURES } \\
\hline & $\begin{array}{c}\text { Density } \\
(1-0)\end{array}$ & $\begin{array}{c}\text { Inclusiveness } \\
\%\end{array}$ & $\begin{array}{c}\text { Reachability } \\
\%\end{array}$ & Distance & $\begin{array}{c}\text { Network } \\
\text { Degree } \\
\text { Centralization }\end{array}$ & $\begin{array}{c}\text { \# of } \\
\text { Cliques }\end{array}$ & $\begin{array}{c}\text { Clique } \\
\text { Density }\end{array}$ \\
\hline Boundary & $\mathbf{0 . 0 5 \%}$ & $\mathbf{9 \%}$ & $\mathbf{2 2 \%}$ & $\mathbf{3}$ & $\mathbf{3 0 \%}$ & $\mathbf{1 5}$ & $\mathbf{0 . 1 1}$ \\
\hline Interactions & $\mathbf{0 . 1 9}$ & $\mathbf{3 8 \%}$ & $\mathbf{9 2 . 5 \%}$ & $\mathbf{2}$ & $\mathbf{7 9 \%}$ & $\mathbf{3 3}$ & $\mathbf{0 . 7 5}$ \\
\hline Coordination & $\mathbf{0 . 1 5}$ & $\mathbf{3 8 . 1 2 \%}$ & $\mathbf{9 7 . 5 \%}$ & $\mathbf{2}$ & $\mathbf{8 0 . 1 6 \%}$ & $\mathbf{5 7}$ & $\mathbf{0 . 8 4}$ \\
\hline $\begin{array}{c}\text { Communication/ } \\
\text { Information } \\
\text { Exchange }\end{array}$ & $\mathbf{0 . 2 7}$ & $\mathbf{5 4 \%}$ & $\mathbf{9 5 \%}$ & $\mathbf{2}$ & $\mathbf{7 0 \%}$ & $\mathbf{9 6}$ & $\mathbf{0 . 0 2}$ \\
\hline $\begin{array}{c}\text { Support and } \\
\text { Transaction }\end{array}$ & $\mathbf{0 . 1 0}$ & $\mathbf{0 . 1 9}$ & $\mathbf{8 5 \%}$ & $\mathbf{2}$ & $\mathbf{8 2 \%}$ & $\mathbf{5 8}$ & $\mathbf{0 . 4 3}$ \\
\hline
\end{tabular}

Source: [28] 


\section{General Conclusions about the Intra-milieu Networks}

The milieu relations in general are non-cohesive, distant, and more evident at the sub-group level than at the total network. The results of this analysis strongly suggest that there is only a small group of milieu actors that relate to each other while most do not relate or actively participate in the milieu operations. Based on the degree centrality of actors (see appendix A) in the various relational networks, it appears that the main actors that drive the functioning of the milieu in general is a) the group of non-profit high technology organizations composed of the Pittsburgh Technology Council (PTC), the Enterprise Corporation (EC), the Ben Franklin (BF) and b) the Working Together Consortium (WTC), and the Carnegie Mellon University (CMU) entrepreneurial center and central administration. It is due to the high involvement of this limited number of actors that contributes to the relative high network centralization scores. These scores by themselves may give the impression of a cohesive and closely organized high technology supportive milieu. However, when the centrality scores of individual actors are examined in the context of each relational content, we see that with the exception of the handful of organizations the remaining milieu actors, including the banking, venture, and public-sector communities do not appear active and involved in the operations of the milieu. The presence of these actors and their interactions appear as occasional, non-committed, and without any significant contribution to the functioning of the milieu.

\section{B: Intra-Software Relations/Networks}

The main question that guided this part of the analysis was: Do software companies relate with each other? If not, why not? If so, how do they relate to each other? What is the content, and characteristics of their relations?

Existence of cohesive business referral, formal business, assistance/support, communication/interaction and friendship/acquaintance networks provide for a cooperative and supportive software business environment.
Such environments are present in the manufacturing regions of the Third Italy and in the environment of Silicon Valley [56, 10, 57, 13]. Dense relations between companies within a specific spatial environment contribute to the development of trust, embeddedness and localized thickening [58]. These are conditions directly connected with a strong local/regional industry, the development and spread of innovation between firms and indirectly connected to dynamic growth and the supportiveness of the local milieu [59, 51, 52, 60, 61, 62, 63].

General Conclusions about the Intra-Software Relation/Networks: The results of the network analysis provide evidence to suggest the lack of any significant level of connections between software companies. Local software companies act independently without providing or receiving any form of support, assistance, or guidance from or to any of the other companies, and without exhibiting any forms of social or business interaction with other companies. Whatever form of network activity appears in the software industry relations emanates from a group of 30 companies which are the local success stories in terms of their ability to receive local funding, in terms of their business success, and in terms of their popularity attained through the local media coverage. This group of companies holds board positions in the main software related non-profit organizations and it participates in mentoring programs developed by the PHTC and the BF in order to help other companies. The nature of their behavior though through these positions appears as obligatory, non-committed, and occasional.

In her work on the success of Silicon Valley, Saxenian [13] mentioned that one of the main contributing factors was the existence of the dense network of social, support, and economic relations between companies. Based on the results of the previous analysis, it is safe to conclude that the local software industry does not contain the relations present in Silicon Valley, and it does not exhibit any tendency to indicate that such relations may be developed or developing.

Table 8. Results of Network Analysis for Intra- Software Relations / Networks

\begin{tabular}{|c|c|c|c|c|c|c|c|}
\hline \multirow[t]{2}{*}{ Relation / Network } & \multicolumn{7}{|c|}{ RELATION / NETWORK MEASURES } \\
\hline & $\begin{array}{l}\text { Density } \\
(1-0)\end{array}$ & $\begin{array}{c}\text { Inclusiveness } \\
\%\end{array}$ & $\begin{array}{c}\text { Reachability } \\
\%\end{array}$ & Distance & $\begin{array}{c}\text { Network } \\
\text { Degree } \\
\text { Centralization } \\
\% \\
\end{array}$ & $\begin{array}{c}\text { \# of } \\
\text { Cliques }\end{array}$ & $\begin{array}{l}\text { Clique } \\
\text { Density }\end{array}$ \\
\hline Business Referral & 0.01 & $2 \%$ & $1 \%$ & 3.5 & 11 & 28 & 0.03 \\
\hline Formal Business & ---- & ------ & ------ & ----- & ------ & ----- & ---- \\
\hline Support & $\mathbf{0}$ & $\mathbf{0}$ & Non-reachable & 2 & $3 \%$ & $\mathbf{0}$ & $\mathbf{0}$ \\
\hline $\begin{array}{c}\text { Communication \& } \\
\text { Interactions }\end{array}$ & $\mathbf{0}$ & $\mathbf{0}$ & Non-reachable & 2 & $3.4 \%$ & 1 & $\mathbf{0}$ \\
\hline $\begin{array}{l}\text { Friendship \& } \\
\text { Acquaintance }\end{array}$ & 0.09 & $17 \%$ & 8.5 & 2 & $24 \%$ & 4 & $\mathbf{0}$ \\
\hline
\end{tabular}

Source: [28] 


\section{C: The Milieu to Software Industry Relational Context}

The third analysis conducted was that of the relational networks between the milieu and the software industry. The two questions that guided this analysis were:

a) Does the local milieu relate with the software industry? If not, why not? If so, how and what is the content and characteristics of their relations; and b) What has been the local milieu's contribution to the process of creating, sustaining, supporting and expanding the software industry?

This last analysis constitutes a very important part of the study for many reasons. The examination and analysis of the specific relational networks through which the milieu and the software industry interact provides evidence about the actual as opposed the declared and presumed participation of the milieu toward the software industry. It also provides evidence about the organization, structure, and functioning of the milieu in its direct relation to the software industry. The focus of the study on the software industry is unlike previous local studies that have attempted to examine and evaluate the general regional environment in its overall involvement and contribution to the high technology industry. In addition to the network analysis, this last part of the study is informed by the qualitative analysis and evaluation of the milieu in its functioning, and contribution to the software industry. In combination, the qualitative and the network-based analyses of the milieu-to-software industry relations provides a complete picture of the status of the local milieu in its relations with and efforts to support, expand, and sustain the industry.

\section{Milieu to Software Network Analysis}

In this framework, the study examined the relational context within the a) Funding, financing and referral network; b) Guidance, advice and information network; c) Support network and d) Interaction network. It needs to be noted that based on the GREMI literature the main function of the milieu within the guidelines of dynamism and innovation is the provision of support defined to include the above specific networks. The existence of cohesive networks within the milieu characterized by dense, inclusive relations in which software companies have easy access to the resources of the various milieu networks will thus be indicative of a supportive, synergetic, and dynamic milieu. Such a milieu will be able to nurture the conditions that encourage innovation and growth. [64].

The results of the network analysis indicate the existence of a non-cohesive local milieu in terms of its general level of participation and support of the local software industry. The relations/networks are characterized by low density, low inclusiveness and reachability levels making it thus non-connected. This is very evident within the funding, financing, and referral network which examined the relations between the milieu and the software businesses in terms of the milieu's provision of funding, financing, venture capital, business loans, and general financial assistance for business start-up. It also examined the provision of funding/financing referrals and general business referrals from the milieu to the companies that may or may have not led to a business transaction, or to funding or financing. This network as indicated by other research is possibly the simple most important network within the context of any local/regional environment but most importantly within the context of an environment containing an emerging industry as is the software industry in the Pittsburgh regional context. Within the local context as the qualitative analysis revealed, the network is very limited in terms of availability and sources of funds especially when compared to other established or aspiring high-technology environments. The local milieu is also conservative in its allocations, funding, and investment choices. Funding, financing, and investments choices of local high-tech non-profits, banks, and venture capital firms are geared mostly toward most established companies in the more traditional for the region industrial sectors (advanced manufacturing, biomedical technology), and University affiliated companies.

Table 9. Results of Network Analysis for Milieu to Software Relations / Networks

\begin{tabular}{|c|c|c|c|c|c|c|c|}
\hline \multirow{2}{*}{$\begin{array}{l}\text { Relation / } \\
\text { Network }\end{array}$} & \multicolumn{7}{|c|}{ RELATION / NETWORK MEASURES } \\
\hline & $\begin{array}{c}\text { Density } \\
(1-0)\end{array}$ & $\begin{array}{c}\text { Inclusiveness } \\
\%\end{array}$ & $\begin{array}{c}\text { REACHABILITY } \\
\%\end{array}$ & $\begin{array}{c}\text { Distance } \\
\text { Among } \\
\text { Reachable } \\
\text { Pairs }\end{array}$ & $\begin{array}{c}\text { Network } \\
\text { Degree } \\
\text { Centralization } \\
\%\end{array}$ & $\begin{array}{c}\text { \# of } \\
\text { Cliques }\end{array}$ & $\begin{array}{l}\text { Clique } \\
\text { Density }\end{array}$ \\
\hline $\begin{array}{c}\text { Funding } \\
\text { Financing \& } \\
\text { Referral }\end{array}$ & 0.09 & $17 \%$ & $9 \%$ & 1 & $20 \%$ & 4 & $\mathbf{0}$ \\
\hline $\begin{array}{c}\text { Guidance } \\
\text { Advice \& Info. }\end{array}$ & 0.07 & $13.4 \%$ & $6 \%$ & 2 & $19 \%$ & 5 & $\mathbf{0}$ \\
\hline Support & 0.15 & $21 \%$ & $11 \%$ & 1 & $21 \%$ & $\mathbf{0}$ & $\mathbf{0}$ \\
\hline Interactions & --- & --- & --- & --- & --- & --- & --- \\
\hline
\end{tabular}

Source: [28] 

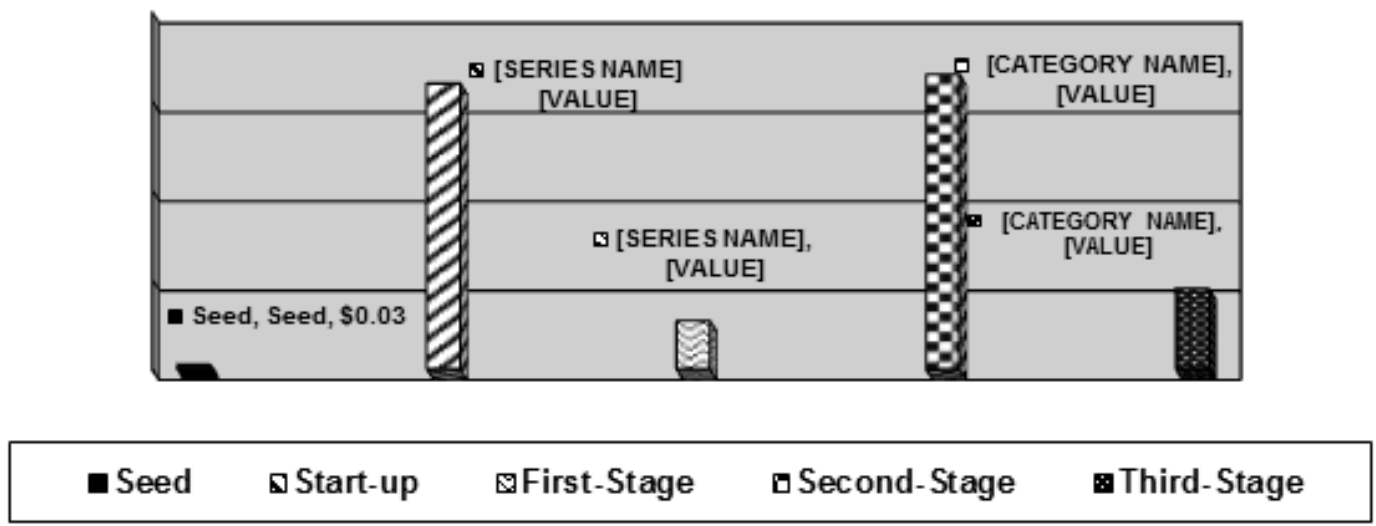

Figure 1. Investment of Local Venture Capital Firms by Stage of Company Development, (1996-1998).

As Figure 1 indicates, the bulk of the local funds went to companies in the second stage of their financing with $\$ 1.65$ million, followed by early stage start-up financing with $\$ 1.60$ million. Seed, first stage, and third stage financing claimed the rest of the funds with seed financing accounting for only .03 percent. There were five local software companies that received venture funds, of which three were in the seed start-up stage and the other two in the first stage of financing. Even if we were to assume that all the money of these two stages went to the three software companies, this amount accounted to only $\$ 300,000$ or .075 percent of the $\$ 4$ million of total local investments. Such a finding verifies again the claims about the limited and conservative nature of local financing.

Exception to this can be the funding of one non-profit, which provides most of the funding to start-up and emerging companies. However, even in this case the funding is not enough to cover the demand, and furthermore it is very closely connected to University affiliated companies. This general environment of the funding, financing and referral network excludes many of the local companies, or those aspiring software aspiring entrepreneurs in need of funds. It also contributes to the fleeing of many local talent to cities and regions such as New York, Silicon Valley, the greater Washington D.C., and etc. depriving thus the local/regional environment from potential successful companies or even a mega success such as Intel, Microsoft. This limited and conservative nature of local capital has also contributed to the fleeing of some companies, which although started in Pittsburgh the local finding and financing resources could not provide for their expansion. Venture capital firms from outside offered such funding and the companies moved outside the region. Such a company was Lycos Inc one of the firs and still very successful Web search engines. The company moved to Boston after being financed by a Boston based venture capital firm. The nature of the local funding and financing environment is also directly connected to the unattractive appearance of the local environment to companies, which look to locate in the region.

Comparable results were provided in regard to the
Guidance Advice \& Information network, and the support network. This network examined the relations between the milieu and the software industry in terms of the milieu's provision of human resources (both scientific and administrative), of software-appropriate training and research programs, as well as in the provision of networking opportunities for companies. The next analysis concerned the interactions network which examined the relations between the milieu and the software companies regarding the milieu's participation in software-related organizations as well as in the milieu's attendance at software related events. The data did not provide evidence to suggest the existence of such a network. This is attributed to the lack of active participation of milieu actors within software-related organizations--with the only exceptions being the three-high technology related non-profits (Pittsburgh High Technology Council, the Enterprise Corporation, and the Software Business Forum-- as well as to the existence of limited software related events.

The results of the network analysis and the individual milieu actors' centrality scores guide the following general conclusion in regard to the milieu's support of and contribution to the software industry: the process of developing and supporting the software industry appears to rest in the efforts of a handful of non-profit, high-technology general and software-specific organizations whose functions and missions, are more appropriately framed within a supportive and advocacy role. Although their efforts are valued, their impact is minimal. These organizations are limited due to the lack of resources, software-related experience, and power necessary to influence the direction of policy and allocation of resources. The efforts of these organizations are supplemented by another handful of individuals, associated with Carnegie Mellon University, the Enterprise Corporation, and three of the 15 local venture funds that have provided early stage financing to a small number of companies. The participation of venture capital and of banks is limited and conservative in nature supporting only companies after their initial stages and after they have 
received the endorsement of Ben Franklin and the EC.

\section{Concluding Remarks}

The results of the analyses indicate that the local/regional milieu is limited, fragmented, non-dynamic, and lacks the necessary financial, organizational, human resources, policy infrastructure and relations to support and sustain the software industry [65, 66, 67]. Many outside the area, during that time were still associating the region with the steel industry, the old boy network way of doing business, and a way of life that did not meet the living style and standards found in some of the high-tech hot beds of the country $[68,69,70]$.

The existing milieu, software, and milieu-to-software related networks are generally non-cohesive; they exhibit non-connected, exclusive, and indirect relations. Whatever appearance of dynamism may exist, is centralized mainly around the operations, efforts, and contributions of the high technology-related non-profit sector, namely the PHTC, $\mathrm{EC}$, and the $\mathrm{BF}$, and the relatively selective and late involvement of CMU. Notable as the efforts of the non-profit sector may be, its abilities are limited and its contribution to the software industry incremental, non-focused, lacking the resources and the wider support from the public, funding, and venture communities. In this context, both the public sector and the venture and financial communities are noticeably absent from actively participating, and interacting with other milieu actors, and with the software industry. Their behavior is conservative, carrying elements of the steel industry mentality as it appears in lending, investing, and financing practices and in the lack of appropriate policy and programs. The contribution of these milieu actors appears occasional. Their relational behavior is opportunistic and lacks the commitment necessary to dynamically support the software industry and to nurture and create the conditions existing within the dynamic environments of the software hot spots.

Within the milieu, the software industry lacks the size, the horizontal and vertical chains, and influence associated with a success story, like Microsoft or Intel. Thus, it mirrors the relational and functional characteristics of its environment. In the context of the software industry, these characteristics include the limited and superficial nature of relations within the support, social, and general transactional networks.

Having identified, presented, analyzed and discussed the elements, conditions, and limits of the local milieu in its relation to the software industry, the question that needs to be addressed is whether or not the local/regional environment can overcome its limitations, how, and how long this will take? Although the region contains many of the elements (universities, high technology related organizations, software companies, and technological know-how) it lacks the mechanisms or conditions to functionally integrate and drive these elements. These conditions based on the GREMI theoretical propositions are:

- Embeddedness, localized thickening [58], or the mysterious alchemy of the environment [52] seen through active local/regional interaction of the economic, financial, social, political, academic, and cultural environments;

- Supportive and committed policy and financial actors and environment; and

- Appropriate and adaptable social and cultural environment.

These conditions, as noted in the GREMI literature, have developed and nurtured over time by the dynamic environments in Silicon Valley, Seattle, Boston, in the industrial districts of the Third Italy, and those high technology environments in France and England [71, 24, $23,72,13,67,73,74,53]$. The Pittsburgh region contained these conditions within its steel, ferrous and non-ferrous metal specialization and had developed them over a period of 100 years of repeated interactions and relations between the production, financial, political, social and cultural local and regional environments. In Silicon Valley, these conditions have developed over a period of roughly 60 years, in Seattle over a period of 20 years, and in some of the newer dynamic areas such as Austin in a period of 12-15 years. This region started to make a presence within the area of software in the last 15 years at the time this data set for the research was collected. This presence though was within the overall regional efforts to revitalize and diversify the regional economy. In addition to the late start, the region did not have a unified idea on how to go about implementing this new phase of the economy [75, 76, 77]. Following the traditional way of approaching and trying to implement economic development, the region, as many others as well, tried to emulate practices from other successful regions. This delayed the development of software appropriate organizational, financial, and support relational contexts and infrastructure which would have contributed to the development of the condition of embeddedness and localized thickening $[78,79,62,61$, 60]. This has also contributed to the continuation of the bureaucratic and policy inertia that has delayed the development of appropriate policy such as tax reform and incentive programs, and general software related business assistance programs.

\section{Methodological Contribution}

In combination, the theoretical framework and methodological approach of this study offers some new possibilities for thinking about, analyzing, practicing, and evaluating regional and local development.

Unlike traditional social science research that measures, classifies, and analyzes, the social world solely on attribute data, network analysis relies on relational data, in 
conjunction with attribute data, which it does not consider mutually exclusive. It emphasizes relational measures which "capture emergent properties of social systems which cannot be measured by simple aggregations of attribute data . . . and which may significantly affect both system performance and the behavior of individual members "32(11)

In this study, the use of network analysis provided the opportunity to evaluate the local milieu in terms of the nature, character, and organization of the interaction of its resources. It also provided the opportunity to measure the cohesiveness or strength of the interactions of the resources [33], which the GREMI literature has hypothesized to be important for dynamic regional growth — but which has not until now been directly measured. For example, Saxenian [13] notes the existence of dense relations between software companies and the existence of a supportive local milieu as crucial factors contributing to the success of Silicon Valley. Similar statements about the importance of dense, cohesive, and supportive relations have been made by other GREMI theorists within the context of innovative environments in France and Italy [80, 81, 82, 83, 10, 52, 59]. However, none of them has provided any quantitative measurement of density, strength, or supportiveness, etc.

Given that this is possibly among the first studies attempting to provide such measurements, more work is needed to validate its methodological and analytical approaches. A study currently in progress will duplicate the current one in terms of the region, industry, and methodology 15 years later. This will validate the methodological framework and provide updated data to provide a comparative evaluation of the efforts of the local milieu. Ideally, this study should also occur within the context of dynamic environments such as Silicon Valley, or those to be found in Germany thus setting benchmarking standards.

This in turn would contribute to validation of the GREMI theoretical propositions, and further inform the theoretical and analytical traditions of regional science and planning. Within the field of regional science, regional environments have been studied and analyzed through methods such as shift-share, input-output, and cluster analysis, which, in broad terms, deal with the movement and aggregation of resources. If used in conjunction with network analysis, these methods could offer a more informed and complete picture of an environment, and more accurately forecast growth potential. For example, these methods allow us to see how resources have moved from one sector to the other or how they cluster under a particular sectoral classification, or how they connect through the supply chains. They do not allow us to evaluate the nature and or strength of relations. If density of relations and supportive local/regional environments are important for dynamic growth, then network analysis will allow an evaluation of the contribution of these resources to the local environment and their potential for dynamic growth.

\section{Theoretical and Practical Implications of the Study}

GREMI's implicit emphasis on local/regional specificity and its reliance on the milieu's networks, synergies, and support systems as the factors that trigger dynamic growth and innovative behaviors instead of emulation, forces us to look at development and planning from within the specific relational contexts of specific milieu [84]. It also highlights the following points:

a) Each environment is unique and is characterized by particular local or regional elements and relational contexts that have developed over time through production, social, cultural interactions.

b) Within a specific project or development initiative, the set of relations, and the set of milieu resources necessary for its implementation and success within a particular milieu may be different from another milieu.

To put these points in a more practical perspective within planning and development practice and policy at the local, community, or regional levels, we should ask the following questions in relation to any give development initiatives or policy:

Do we have a deep understanding of the economic development activity, effort, or project we are trying to undertake? For example, if a city wants to diversify its economic profile into one incorporating computers and communications, do the appropriate actors understand the requirements of the particular industry? These can include sources of funding, financing, venture capital, policy, support organizations, and human resources, etc. In other words, do they know what a specific industry or project requires in order to succeed? This knowledge is important for avoiding unnecessary public expenditures. For example, is construction of industrial parks or incubators necessary when they do not know whether they will be occupied by the industry they are trying to attract or develop? It is also important in the sense that local policy makers and planners may not know if the spaces they have developed are appropriate for the needs of businesses that belong to the industry they want to attract.

Economic and community development practitioners and planners have often been forced either by policy makers or by the availability of targeted funds to undertake projects which do not have much chance of benefiting a city or region because they are not appropriate for the local environment. For example, during the 1980s, 1990s, and early 2000s an important focus in the Pittsburgh economic region and others around the country was the development of business incubators and industrial parks. Millions of dollars were spent for land clearance and construction, yet today many of them today are outdated and remain underutilized because there were no businesses to occupy them, or the spaces were inappropriate for the businesses that did want to move in. Another more recent example 
involves the efforts of many cities throughout the US to revitalize their economies by trying to develop high tech industries. This apparently seems to have benefited some cities but with no knowledge on whether such an activity will benefit or succeed in a different setting $[85,86]$.

Having understood the needs of the industry/project we can then ask: Do we have what we need for the particular activity? Can we create, attract, and sustain the networks and resources we need? The answers involve evaluating the city's or region's ability to provide both the resources and the conditions needed for the success of the economic activity. This is the point where the methodological and analytical framework of this study can be used to reveal the existence or absence of relations, and resources, evaluate their structure and limitations and thus guide local/regional efforts and inform appropriate policy making.

An implicit point in addressing the issue of answering this question is understood and revealed the local dynamism as exhibited in cities such as San Francisco, Seattle, Boston, Austin, and in regions such as Silicon Valley, the Third Italy, and Toyota City. Within the realm of economic and community development, dynamism under the GREMI propositions involves the existence of strong networks of relations between:

a) Elements of the economic activity or industry;

b) The economic activity and the actors of its milieu (public organizations, funding and financing organizations, academic and training institutions, local government, support organizations, etc.);

c) The appropriate milieu actors.

In other words, for an environment to become dynamic in relation to a particular economic or development activity, the parts involved in such activity need to be able to work well together and to be connected through various kinds of relationships. These kinds of relationships cannot be created overnight or superimposed upon existing structures $[87,88,89]$. They develop over time. The exact nature and content of relationships will depend on the requirements of a particular economic activity [89]. Based on this study of the Pittsburgh region's software industry during the 2000s, the relations that were determined as appropriate for the development and sustainability of the industry included transaction relations, boundary penetration relations, support and interaction relations, and friendship relationships. Other kinds of economic development activities or other related projects may require different kinds of relationships.

A last point that is explicitly highlighted in the GREMI framework and in this study, is that of the importance of local/regional specificity in terms of sustainable development-which should be a fundamental goal of any economic development initiative. The main point is that sustainable development does not occur through the duplication of development efforts that occurred outside a specific environment. We should certainly study other areas' development efforts. However, they should only be used as points of inspiration and as generic models rather than specific blueprints $[64,22]$.

Development efforts that are not based on the local/regional dynamics, abilities, know-how, and resources, and those that do not include an understanding of the requirements of the new economic activities or of any development scheme simply lead to wasted efforts and resources [91, 89]. Sustainable development requires strong support networks that constitute the skeleton of a specific milieu; these result from attempts to create and cultivate new networks as deemed necessary by the new economic direction(s) that a region is undertaking. Can the Pittsburgh economic region do this in terms of its developing software industry? Optimistically yes but realistically maybe and that after considering all the points made in this last section and after answering all the questions that implicitly and explicitly expressed in GREMI and addressed in this study.

\section{REFERENCES}

[1] Sinozic T, Franz Todtling F, (2015). Adaptation and change in creative clusters: findings from Vienna's new media sector. European Planning Studies. 1992 October; 23(10): 1975-1992.

[2] Todtling F, Trippl M. Transformation of Regional Innovation Systems: From Old Legacies towards New Development Paths. Paper presented at: The $52^{\text {nd }}$ European Regional Science Association Congress. ERSA 12; 2012 August 21-25; Bratislava, Slovakia.

[3] Deitrick Sabina. The post-industrial revitalization of Pittsburgh: myths and evidence. Community Development Journal. 1999 January; 34 (1): 4-12.

[4] Aydalot, P. and Keeble, D. editors. High technology industry and innovative environments: the European experience. London: Routledge; b1988.

[5] Cooke P, Asheim B, Boschma R, Martin R, Schwartz D, Tödtling F, editors. Handbook of regional innovation and growth. Glasgow (U.K.): Edward Elgar Publishing; 2011. (no 13482).

[6] Cooke P, DeLaurentis C, Tödtling F, Trippl M. Regional Knowledge Economies. Glasgow (U.K.): Edward Elgar Publishing; 2007. (no 3957).

[7] Camagni R. Territorial capital and regional growth. In R. Capello R, and Nijcamp P, editors. Handbook on regional growth and development theories. Cheltenham (UK): Edward Elgar; 2009.

[8] Boisot M. Information Space: A framework for learning in organizations, institutions and culture. New York: Routledge; 1995.

[9] Duysters G. The dynamics of technical innovation. Brookfield, VT: Edward Elgar; 1996.

[10] Bergman, E., Maier, G., Todtling, F., editors. Regions 
reconsidered: economic networks, innovation and regional development in industrialized countries. London: Mansell Publishing Limited; 1991.

[11] Kamath, A. Industrial innovation, networks, and economic development: informal information sharing in low-technology clusters in India New York: Routledge; 2015.

[12] Camagni R. Creativity, Culture, and Urban Milieux. In Fusco L., Baycan T, Nijcamp P, editors. Sustainable City and Creativity. Farnham (UK): Ashgate. 2011.

[13] Saxenian AL. Regional Advantage: Culture and Competition in Silicon Valley and Route 128. Cambridge (MA): Harvard University Press; 1994.

[14] Bertuglia, C. Lombardo, S., Nijkamp, P. Innovative Behaviour in Space and Time. New York: Springer Verlag; 1997.

[15] Ratti, R., Bramanti, A., Gordon, R. editors. The dynamics of Innovative Regions. Brookfield, (VT): Ashgate; 1997.

[16] Maillat, D. The innovation process and the role of the milieu. In Bergman EG, Maier GF, Todtling F, editors. Regions reconsidered: economic networks, innovation and local development in industrialized countries. London: Mansell Publishing Limited; 1991.

[17] Arora A, Gambardella A, Torrisi S. In the footsteps of the Silicon Valley? Indian and Irish software in the international division of labor. Stanford University: Stanford Institute for Economic Policy Research; 2001. SIEPR Discussion Paper No. 00-4.

[18] Torrisi S. (1998). Industrial organization and innovation: an international study of the software industry. Cheltenham (UK): Edward Elgar Publishing; 1998.

[19] Gordon, R. Innovation, industrial networks and high-technology regions. In Camagni R, editor. Innovation networks. London: Belhaven Press; 1991. p. 174-195.

[20] Camagni R. (2009). Territorial capital and regional growth. In Capello R, Nijcamp P. Handbook on regional growth and development theories. Cheltenham: Edward Elgar; 2009. p. $118-132$.

[21] Camagni R. (2002). On the concept of territorial competitiveness: sound or misleading? Urban Studies. 2002 December; 39 (13): 2395-2412.

[22] Kaufmann A, Todtling F. (2001). Science-industry interaction in the process of innovation: the importance of boundary-crossing between systems," Research Policy, 2001.30(5): 791-804.

[23] Cook P, Morgan K. The associational economy: firms, regions and innovation. Oxford: Oxford University Press; 1998.

[24] Cooke, P. and Morgan, K. The Network paradigm - new departures in corporate and regional development. Environment and Planning: Society and Space. 1993. 11: 543-564.

[25] Simmie J. Learning city regions: theory and practice in private and public sector spatial planning. Planning Practice and Research. 2012. 27(4):423-439.
[26] Simmie J. Innovation and space: a critical review of the literature. Regional Studies. 2005. 39: 789-804.

[27] Simmie, J, editor. Innovation networks and learning regions. New York: Routledge; 2005.

[28] Rigopoulou A. Anatomy of regional milieu: the software industry in the Pittsburgh economic region. [Dissertation]. Pittsburgh (PA): University of Pittsburgh; 2000.

[29] Parkhe A, Wasserman S, Ralston D. New frontiers in network theory development. Academy of Management Review. 2006 July; (31) 3: 560-568.

[30] Carrington P, Scott J, Wasserman S, editors. (2005). Models and methods in social network analysis. Cambridge (U.K): Cambridge University Press; 2005.

[31] Wasserman S. Faust K. Social network analysis: methods and applications. Cambridge (U.K): Cambridge University Press; 1994.

[32] Knoke D. Kuklinski J. (1982). Network analysis. Beverly Hills: Sage Publications; 1982.

[33] Knoke D,Yang S. Social network analysis. Thousand Oaks (CA): SAGE Publications; 2008.

[34] Borgatti S, Everett M. (1999). Models of core/periphery structures. Social Networks. 1999. 21:375-395.

[35] Borgatti S, Everett M, Freeman L. UCINET for Windows: Software for Social Network Analysis. Harvard, (MA): Analytic Technologies; 2002.

[36] Mitchell J. Social Networks in Urban Settings. Manchester: Manchester University Press; 1969a

[37] Becattini, G, Bellandi M, DePropris L, editors. A handbook on industrial districts. U.K.: Edward Elgar; 2011.

[38] Boix R, Galleto V. Innovation and industrial districts: a first approach to the measurement and determinant of the i-district effect. Regional Science: 2009.43(9):1117-1133.

[39] Boschma R. Proximity and innovation: a critical assessment. Regional Science: 2005.39(1): 61-74.

[40] Ache, P. Cities in old industrial regions between local innovative milieu and urban governance: reflections on city region governance. European Planning Studies: 2000. 8(6), 693-709.

[41] Gordon, R. Structural change, strategic alliances and the spatial reorganization of Silicon Valley's semiconductor industry. Paper presented at the: GREMI Conference; 1991; Milan, Italy.

[42] Cooke, P. Planet Europe: network approaches to regional innovation and technology management. Technology Management: 1995. 2:18-30.

[43] Camagni R. Introduction: from the local "milieu" to innovation through co-operation networks. In Camagni R, editor. Innovation networks. London: Belhaven Press; 1991a. p.1-9.

[44] Scott, A. High Technology and Territorial Development: The Rise of the Orange Country Complex, 1955-1984. Urban Geography, 1989.71: 3-45. 
[45] Scott, A. Flexible Production Systems and Regional Development: The Rise of New Industrial Spaces in North America and Western Europe. International Journal of Urban and Regional Research, 1988. 12(2): 171-185.

[46] Scott J. Social Network Analysis. New York: Sage Publications Inc; 2012.

[47] Freeman L. The development of social network analysis: a study in the sociology of science. Vancouver, BC Canada: Empirical Press; 2004

[48] Freeman L. Centrality in social networks: conceptual clarification. Social Networks, 1979. 1(1): 12-24

[49] Komninos N. The age of intelligent cities: smart environments and innovation for all Strategies. New York: Routledge; 2014

[50] Keeble D, Lowson, C, Moore B, Wilkinson F. (1999). Collective learning processes, networking and institutional thickness in the Cambridge region. Regional Studies, 1999. 33 (4):319-332.

[51] Aydalot P, Keeble, D, editors. High technology industry and innovative environments: the European experience. London: Routledge; $1988 \mathrm{~b}$

[52] Planque B. Innovation networks. France: Regional Economic Centre Universite d'Aix Marseille III; 1991.

[53] Becattini, G. The Marshallian industrial district as a socio-economic notion. In Pyke F, Becattini G, editors. Industrial districts and inter-firm co-operation in Italy. Geneva: International Institute for Labour Studies; 1990. p. $152-170$

[54] Harrison, B. Lean and mean: The changing landscape of corporate power in the age of flexibility. New York: Basic Books; 1994

[55] Harrison, B. (1991). Industrial Districts: Old Wine in New Bottles? Regional Studies, 1991. 26(5): 469-483.

[56] Bruce H. Economic development and industrial relations in a small firm economy: the experience of metal workers in Emilia-Romagna [master's thesis]. New York: City University of New York; 1990.

[57] Saxenian, A. The origins and dynamics of production networks in Silicon Valley. Research Policy, 1991. 20(4): 423-437.

[58] Granovetter, M. Economic action and social structure: The problem of embeddedness. American Journal of Sociology, 1985. 91(3): 481-510.

[59] Aydalot, P, editor. Mileux Innovateurs en Europe. Paris: GREMI; 1986

[60] Grabher, G. The embedded firm: on the Socio-economics of industrial networks. London: Routledge; 1993.

[61] Grabher G. Ecologies of creativity: The village, the group, and the hierarchic organisation of the British Advertising Industry Environment and Planning, 2001. 33(2): 351-374.

[62] Grabher G, Ibert O. Bad company? The ambiguity of personal knowledge networks. Journal of Economic Geography, 2005. 6 (3):251-271.

[63] Grupp, H. Foundations of the Economics of Innovation:
Theory Measurement and Practice. U.K.: Cheltenham; 1998

[64] Kaufmann A, Tödtling, F. Systems of innovation in traditional industrial regions: The case of Styria in a Comparative Perspective', Regional Studies, 2000. 34 (1): 29-40.

[65] Feldman M, Schoenberger E. Difference in economic geography. Environment and Planning, 2016.48(10): 2089-2092.

[66] Feldman M. The geography of innovation. Boston: Kluner Academic; 1994.

[67] Feldman M, Florida R. The Geographic sources of innovation: technological infrastructure and product innovation in the United States. Annals of the Association of American Geographers, 1994. 84(2): 210-229.

[68] Labich K. The best cities for knowledge Workers. Fortune. 1993 November 15; 50-78.

[69] Birch D. Where good jobs grow? Fortune, 1993 June 14; 22.

[70] Feldman M, Lowe N. Evidence-based economic development policy. Innovations: Technology, Governance, Globalization, 2017:11(3), 34-49.

[71] Feldman, M.P. and M. Storper, Economic Growth and economic development: Geographic dimensions, definitions, and disparities. In: Gordon C, Feldman M, Gertler M, Wojcik D, editors. The New Handbook of Economic Geography. Oxford University Press, Oxford, UK; 2016. p. 182-204.

[72] Bathelt H, Glückler J. The Relational Economy: Geographies of Knowing and Learning. U.K.: Oxford University Press; 2008.

[73] Crevoisier O. The Innovative Milieus Approach: Toward a Territorialized Understanding of the Economy? Economic Geography. 2004. 80(4):367 - 379 .

[74] Crevoisier, O. and Maillat, D. (1991). Milieu, industrial organization and territorial production systems: toward a new theory of spatial development. In R., Camagni R. editor. Innovation networks. London: Belhaven Press; 1991. p. 13-34.

[75] Florida, R. Thinking differently about the region: Southwestern Pennsylvania's manufacturing and technology assets: Pittsburgh High Technology Council and Southwestern Pennsylvania Resource Center; 1994.

[76] Florida R., Gleeson R. Toward a shared vision for Pittsburgh and Southwestern Pennsylvania: A Report by the White Paper Committee: Pittsburgh/ Allegheny Conference on Community Development; 1993.

[77] Florida, R. Design for high performance manufacturing infrastructure: Carnegie Mellon University; 1992.

[78] Todtling F, Trippl M. How do firms acquire knowledge in different sectoral and regional contexts? In Shearmur R, Carrincazeaux C, Doloreux D, editors. Handbook on the Geographies of Innovation. Edward Elgar; 2016: p.142-154.

[79] Todtling, F. (1994b). The uneven landscape of innovation poles: local embeddedness and global networks. In Amin A., Thrift, N, editors. Globalization, Institutions, and Regional Development in Europe. New York: Oxford University 
Press; 1994b. p 68-90.

[80] Caniëls M, Romijn. H. What drives innovativeness in industrial clusters? Transcending the debate. Cambridge Journal of Economics. 2005.29(4): 497-515.

[81] Caniels M, Verspagen B. (2001). "Barriers to knowledge spillovers and regional convergence in an evolutionary model" Journal of Evolutionary Economics. 2001. 11(3):307-329

[82] Ratti, R., Bramanti, A., Gordon, R., editors. The dynamics of Innovative regions. Brookfield (Vt): Ashgate; 1997.

[83] Archibugi D, Cesaratto, S, Sirilli, G. Sources of Innovative Activities and Industrial Organization in Italy. Research Policy. 1991.4(20): 299-313

[84] Camagni R. (2008) Regional competitiveness: towards a concept of territorial capital. In: Capello R, Camagni R., Fratesi U. Modelling regional scenarios for the enlarged Europe: advances in spatial science. Berlin/ Heidelberg: Springer; 2008. p.33-47.

[85] Thomas K. Creating regional cultures of innovation? The regional innovations strategies in England and Scotland.
Regional Studies. 2000. 34(2):190-198.

[86] Lovering, J. Theory led by policy: the inadequacies of the "new regionalism". International Journal of Urban and Regional Research. 1999. 23(2):379-395.

[87] Vazquez-Barquero A. Endogenous development: networking, innovation, institutions and cities. USA: Routledge; 2002.

[88] Isaksen A. Building regional innovation systems: is endogenous industrial development possible in the global economy? Canadian Journal of Regional Science/Revue Canadienne des sciences regionals. 2001: XXIV (1): 101-120.

[89] Thomas K. Creating regional cultures of innovation? The regional innovation strategies in England and Scotland. Regional Studies. 2000. 34(2):190-198.

[90] Breschi S, Malarba F, Orsenigo L. Technological Regimes and Schumpeterian Patterns of Innovation. Economic Journal. 2000. 110(463):388-410

[91] Moulaert F, Sekia F. Territorial innovation models: a critical survey. Regional Science. 2003. 37(3): 289-302. 